\section{The Speech Act of Request in Computer-Mediated Communication}

\author{
Maria Miwita Rosari \\ Graduate Program of Linguistics \\ Universitas Gadjah Mada \\ mariamiwitarosari@gmail.com
}

\begin{abstract}
Through conversation ones establish relationship with others and keep channels open for further relationships. Politeness strategies and issues have been the focus of a number of studies. The way ones request for something to others depends on some factors such as the context they are in and the interlocutors they talk to. This article aims at developing the latest discussion on politeness phenomena by paying attention to the specifics of Computer-Mediated Communication (CMC) settings specifically an online discussion forum. This article attempts to identify how speech act of request is performed in Top Law School (TLS) online discussion forum. The data were analyzed to observe the forms of speech act of request and the types of speech act of request performed in the online discussion forum. The findings of this paper revealed that the forms of speech act of request are expressed by declarative, interrogative, and imperative sentence. Moreover, the types of speech act of request employed by the users are directive, indirective, and literal speech acts. The writer believes that the study will be beneficial and a good reference for future researchers in conducting research on pragmatics under the same topic. Hopefully, it will enrich readers' knowledge and understanding of the speech act of request and the politeness in CMC.
\end{abstract}

Keywords: speech act; request; politeness; CMC; discussion forum

\title{
INTRODUCTION
}

Requesting is one of the most basic and common activities in daily and social interaction. In daily activities, whenever ones live, whatever language ones speak, whatever work ones do, whatever status ones have in society, almost every day in lives, ones ask someone to do something. In other words, people make a request over someone. At first sight it appears that requests are fairly simple and well-defined as speech acts. As stated by Searle that to request counts as an expression of a wish or desire $(1969$, p. 65). It is in line with Trosborg (1995, p. 187) who mentioned that a request is a speech act whereby a requester conveys to a requestee that he/she wants the requestee to perform an act which is for the benefit of the requester. A request may be the act for requesting for an object or information. Requesting is considered as performing illocutionary acts. Requesting a thing to someone who one is very familiar with will be different to someone who is less familiar. The way ones speak, for instance the level of formality and the politeness will be distinctive.

In this era, to maintain relations with people who far physically is through communication technologies, for instance computers, the internet, and mobile phones. Baron (2008), for instance, has shown how the electronically-mediated technologies are changing the way people communicate and relate to one another. Technology has revolutionized the way people communicate with each other. Rather than rely solely on face-to-face communication, people have a wide variety of technology-mediated in communicating. In daily interaction, ones may use mobile phones to talk to their families or friends, send emails to colleagues, and chat to other people with the same interest to stay informed about a particular information through online discussion forum.

Online discussion forum allows users with the same interest to share or ask anything related to the issue discussed. Online discussion forum (ODF) is a web-based application that brings people together with shared interest and mindset (Biriyai \& Thomas, 2014). This study is based on what is publicly available on internet. The rapid development of technology has changed the way people interact each other. People are interacting within each other inside the internet where they communicate through device-based mediation. This phenomena is referred to Computer-Mediated Communication (CMC). 
A number of terms have been used to refer to the language used in the electronic communication, 'Computer-Mediated Communication' (Herring, 1996), 'Electronic Discourse' (Davis \& Brewer, 1997), 'Netspeak' (Crystal, 2001). Internet allows people to interact with the other in a multi-party conversation online, either asynchronously, in a postponed time or synchronously, in a real time. In synchronous setting, a user enters a chat room and joins an ongoing conversation in a real time. Asynchronous setting, by contrast, the interactions place to a central address, but they are stored and made available to members of the group only upon demand, so the members can join with the discussion even after an appreciable period has passed (Crystal, 2001, p. 130).

Online discussion forums, the main source of this study, is a type of asynchronous communication. Hewitt (2005, p. 568) argued that one of the most common of asynchronous communication is the "threaded" discussion. Further, Hewitt defined it as "a hierarchically organized collection of notes in which all notes but one is written as 'replies' to earlier notes." People join a group because they know the topic they are talking about. They are assumed to be equals and will be judged as such based on the basis of the quality of their messages. Language, hence, becomes the primary means of establishing and maintaining group membership and identity.

People cannot predict in any details the nature of the transformations that technologies will bring, but one aspect of life that will certainly be affected is communication (Kiesler, Siegel, \& McGuire, 1984 , p. 1123). Communication is a way to maintain social contact with others. In all these communicative events, language plays an important role. It is, therefore, not surprising that the language employed on $\mathrm{CMC}$, in recent times, has aroused scholarly interest among researchers (Soffer, 2010; Walther, 2012; Zappavigna, 2012; Eisenstein, 2013; Akkaya, 2014; Stæhr \& Madsen, 2015; Chun \& Smith, 2016; KhosraviNik, 2017).

This article focuses on the request strategies employed in computer-mediated communication related to politeness. A number of politeness studies have been carried out from the perspective of linguistic pragmatics and sociolinguistics (Watts, 2003; Wierzbicka, 2003; Christie, 2005). The study of politeness and speech acts has also been discussed in the literature field (Darics, 2010; Locher, 2010; Taleghani-Nikazm, 2012, Shum \& Lee, 2013; Kavanagh, 2016; Flores-Salgado \& CastineiraBenitez, 2018).

In Journal of Computer-Mediated Communication, Nastri, Pena, and Hancock (2006) investigated the extent to which these communicative goals are reflected in the language structure of away messages. The article, particularly, examined the specific types of utterances, or speech acts, used by participants in creating their away messages which can tell the writers about the structural and functional properties of away messages through the production of 483 away messages employed by 44 participants. The article also attempted to analyse the use of non-standard orthography (e.g., LOL) and humour. Although many different taxonomies of speech acts have been presented, the article used one well-known taxonomy that has been used in natural language processing and other CMC research proposed by Searle (1969, 1979).

The study used a sample population consisting 49 undergraduate students. The participants completed a questionnaire pertaining to their computer and Instant Messaging use. The results showed that it was worth noting the participants appear to use away message far more frequently than the message features of other communication technologies. Furthermore, the messages were constructed primarily with assertives, followed by expressives and commisives, but rarely with directives. It confirmed that away messages tend to reflect both informational and entertainment goals. Those findings were discussed in terms of computer-mediated discourse and online-self presentation.

In more recent study, Yazdanfar and Bonyadi (2016) conducted a comparative study of request speech act in Persian and English. The study, specifically, attempted to explore the request strategies used in daily interaction of Persian and English speakers based on directness levels and supportive moves. The writers observed and transcribed the requestive utterances in Persian and English TV series. The utterances were then classified based on Blum-Kulka and Olshtain's Cross-Cultural Study of Speech Act Realization Pattern (CCSARP) for the directness level and internal and external mitigation devices. 
The results showed that although the speakers of both languages opted for the direct level as their most frequently used strategy in their daily interactions, the English speakers used more conventionally indirect strategies than the Persian speakers did. While, the Persian speakers used more non-conventionally indirect strategies than the English speakers did. The writers concluded that it might be due to the fact that Western cultures were under the construct of individualism, which gave all human beings the right to think and judge independently. Moreover, with regard to mitigation devices, the results revealed that the English speakers in the English TV series used those devices to decrease the imposition of the requests more than the Persian speakers. The English speakers preferred internal to external mitigation devices. It could be inferred that American English speakers mitigated their requests when they were addressing their family members and friends since the requests addressed to the interlocutors with the same social position.

Those studies mentioned above are related to politeness and speech acts analysis. However, there appears to be far fewer studies focusing on the speech act of request in CMC. In this regard, the writer sees the relation of the speech act of request and the politeness phenomenon in CMC settings. This relation is worth to be analyzed since there is a connection that can be linked between those two. This phenomenon raises curiosity that can be the source of material for this study. Moreover, the increasing participation of users in online discussions is attracting the attention of the writer in conducting research at this area of communication as a potential source of knowledge.

This study examines posting messages taken from the online discussion forum namely Top Law School (TLS) focusing on the language use of the users when requesting an information, a favor, and/or a thing to the other users. The writer focuses on the posting messages in one of the threads of TLS forum with 107 postings in total. TLS forums have been focused primarily on law school applicants with discussion forums such as the law school admissions forum, the law school admission test preparation forum, the personal statement forum, the choosing a law school forum, and so on.

Within this TLS forum, the writer found the forms and the types of speech act of requesting performed by the members of TLS forum. The following example may be useful to clarify the background of the study.

(1) Which question did everyone choose for the optional essay?

The type of the posting message (1) is a direct request. The user asked the other users about their choices for the optional essay. The user wanted to know and get information about it. The form of the request strategy performed by the user in posting message (1) is interrogative.

This article will thus address two research questions: 1) what are the forms of speech act of request performed by members in Top Law School discussion forum? and 2) what are the types of speech act of request employed by members in Top Law School discussion forum?.

The data were gathered through the posting messages in Top Law School discussion forum captured by the thread Law School Acceptances, Denials, and Waitlists. The 107 posting messages collected were then analyzed and classified to find the forms and the types of speech act of request. The mode classification based on Searle (1969). The study was categorized as qualitative research since the data collected were in the forms of descriptive rather than statistical data. After analyzing the data, the results will be presented descriptively.

Many pioneering linguists in the field of pragmatics agree to the fundamental view that the use of language is a context-dependent (Lakoff, 1972; Hymes, 1974; Halliday, 1978; Yule, 1996; Watts, 2003, Parker \& Riley, 2014). Parker and Riley (2014, p. 28) stated that pragmatic is the study of how language is affected by the context in which it occurs. It is in line with Yule (1996) who argued that pragmatic is the science of studying about the meaning delivered by the speaker and interpreted by the listener. Both Parker and Riley and Yule agreed that pragmatic is about contextual meaning including the effect on an utterance and the goal that the speaker intends to deliver through expression. It is in line with Mackinlay and Genesereth (1985) who defined language as a set of conventions that a speaker and a hearer have for constructing and interpreting the messages. By delivering messages through a language, both speakers and hearers must be familiar with the context of situations in order to be able to express meaningful utterances and understand the utterances well. 
The term of speech act will be explained as it is considered to be very important for this paper. Speech act theory was first proposed by Austin in 1962 who believes that an utterance can be used to perform an act. In other words, actions carried out through speech are called speech acts. As stated by Chaer (2004, p. 16) that speech acts are individual symptoms which their continuity is determined by the speaker's language ability in dealing with certain situations. Each speech act has two facets, namely a locutionary act or the act of saying something and an illocutionary act or the act of doing something. Searle (1976) classified illocutionary acts into six types called representative, directive, question, commissive, expressive, and declaration.

Requesting is part of the directive speech act which is the action that manifests the effort on the part of the speakers so that the hearers do something to achieve the goal. Speech act of request expresses the desire of the speaker trying to get the hearer to do something, for instance the utterance 'shut the door'. Looking more closely at the cost-benefit segment, the requesting in speech act is an illocutionary act whose benefits the speaker and the costs are to the hearer. This action is different from the speech act suggesting which the benefit is in the hearer. In addition, Blum-Kulka (1989) originally introduced the distinction between the three levels of directness of a request, namely direct (characterized by the use of imperatives), conventionally indirect (the use of forms that downgrade the degree of imposition), and, non-conventionally indirect (the use of hints to let the hearer know what the speaker intends).

\section{RESULTS AND DISCUSSIONS}

This section provides a qualitative analysis of the various forms and types of speech act of request employed by the users of TLS discussion forum. At the outset, it is important to highlight that the posting messages remain unedited and are presented as originally as posted by the users themselves.

Having analysed the data, the forms of speech act of request employed by the TLS users are declarative, imperative, and interrogative. The results showed that the TLS users mostly expressed the speech act of request in the form of an interrogative. Furthermore, the most frequent type of speech act of request employed by the TLS users is a directive. The discussion of each result as follows.

\section{The Form of Speech Act of Requesting}

The forms of speech act of requesting employed by the TLS users are declarative, imperative, and interrogative sentence. The following discussion of each form is based on the most frequent form of speech act of requesting.

\section{a. Interrogative Sentence}

The example (1) shows the speech act of requesting in the form of interrogative sentences. The example (1) is an interrogative and so expressed a question. The user's goal in asking a question is to get an answer. As in the posting message (1), the TLS user asked the other users to tell him/her about the time they applied or interviewed. The user posted the message since he/she did not know and wanted to get the information about that. The user asked about the information in a polite way by using the words 'do you mind'. It is possibly because he/she is the new member of the discussion forum and does not familiar with the other users.

The example (2) and (3) also show the speech act of requesting in the form of interrogative sentence. The example (2) shows that the TLS user expressed the speech act of requesting to ask about the application. In requesting the information, the user also mentioned the condition why he/she did not get the response after completed the process. Furthermore, the example (3) shows the speech act of requesting in the form of interrogative sentence as well. The TLS user asked about an information to the other users and ensured that he/she did not miss a thing. The illustrative examples from the data are presented below.

(1) Congrats! Do you mind telling when you applied and if/when you interviewed?

(2) How long did it take for your application to go from received to complete? I didn't realize that the 4 week mark started from when your application was marked complete and am now frantically trying to figure out when I should expect a response. I also applied ED (application was received on October 5 th and haven't heard back yet. 
(3) Okay when are we getting scholly info?! Did I miss a form or something?

\section{b. Declarative Sentence}

In requesting something, the TLS users expressed the speech act of request in a form of declarative sentence. Captured mainly in declaratives, the requests were used by the TLS user to ask information from other TLS users. The illustrative examples from the data are presented as follows.

(4) Each year, a large number of candidates submit applications to Georgetown Law early in the process. The high quality of this group makes the Committee's decisions extremely difficult. Please be aware that only a small number of early applicants have their applications held, and a number of those applicants in past years have subsequently been admitted."

Not really sure what to make of it.

(5) Would love to see some movement on this thread! On the waitlist here and desperately looking for some support.

The example (4) and (5) show the speech act of requesting in the form of declarative sentences. In example (4), the user tacitly instructed the other users to be aware of the process of application submission. In example (5), the user expresses the speech act of request in the form of declarative. It can be inferred explicitly that the user actual intention is to look for some support.

\section{c. Imperative Sentence}

Imperatives are also used with a weaker directive force in requests, warning, and so on. As stated by Searle (1975) that directives are used by the speakers to get the addressee to do something. Schmerling (1982) found out that imperatives have a wide range of uses going beyond even the extended sense of directive, for instance they can be used to merely express a wish, to permit, to offer or invite, and also to request. In the case of an imperative sentence, one must at least understand what he/she is supposed to do in order to bring about the state of affairs desired by the speaker. In addition, the hearer must understand the speaker's expectation that he can successfully impose his/her will.

The imperative sentence used by the TLS users to comprise a request. In example (6) below shows the implications of the TLS user desire. The user asked for a help because his/her requirement went blank.

(6) My requirement section went just blank as well... WHAT IS GOING ONNNN Sumone please help

\section{The Type of Speech Act of Requesting}

In performing the speech act of request, ones can do it directly, indirectly, and literally by way of performing another speech act or depending on how people are using their words. As an example, one can make a request by way of making a statement by uttering "I am hungry". It can be concluded that when an illocutionary act is performed indirectly, it is performed by way of performing some other one directly. The TLS users performed the speech act of request directly, indirectly, and literally. The discussion of each type as follows.

\section{a. Direct Speech}

Direct speech act of requesting is asking for an information or something explicitly. The direct request mostly uses the pronoun, for instance "I", "you" followed by verb expressed the speaker's wants. The direct request is the frequent used type of speech act of requesting. The illustrative of the examples of data as follows.

(7) Which question did everyone choose for the optional essay?

(8) Cong! When did you get the interview email? Are you RD or ED?

(9) For those of you who have been admitted, did anything in your application status checker change? 
(10) Congrats everyone! Quick question: did your acceptance letters say anything about scholarships/merit aid?

As in example (7), the TLS user directly asked for an information to the other users about their choice for the optional essay. While the example (8) showed the TLS user explicitily and directly asked about the interview email to the other users. In example (9), the TLS user asked to the other user who have been admitted about the application status. The example (10) showed the user used the "yes/no question" which indicated the direct request for an information.

Direct request is most frequent used by TLS users. It is possibly because the discussion is not a face-to-face interaction which makes the users prefer to use direct request rather than indirect request to avoid the misunderstanding.

\section{b. Indirect Speech}

The indirect speech means the speaker requests something implicitly. The indirect speech act of requesting makes the requests seems politer. In other words, indirectness can be used to show politeness. The illustrative examples of the data are presented as follows.

(11) Would love to see some movement on this thread! On the waitlist here and desperately looking for some support.

(12) So I'm SPWL and straight up said I'd attend if admitted in my reply to the feeler email and video a couple weeks ago. But I've not hear anything since and I starting to worry after hear that they've sent feelers and interview requests to some people.

In example (11), the TLS user performed the speech act of request indirectly. The user did not ask explicitly about his/her hopes. In example (12), the TLS user explained about his/her problems. However, the user did not ask explicitly about the solution but the user let the other user to interpret his/her intention.

\section{c. Literal Speech}

The literal speech act is related to a request that puts the speaker's intention to let the requestee interprets and takes the action. The request asked by the speaker is the literal meaning of the speaker's wants. The illustrative examples of the data as follows.

(13) I had my alumni interview on October 29. Did anyone else interview around that time? Does anyone know how long it normally takes to hear back? Thanks

(14) Check in GULC RD.

But I did not write an optional essay. I am afraid that admission office will see it as negative? How does it influence my chance of admission if I did not write an optional essay? Can I transfer my RD to ED?

In example (13), the TLS user asked for information to the other users by firstly explaining about the situation. The user did not ask to a certain user but he/she threw the question to anyone. The user let the other users who had the same problem to answer the questions. The example (14) showed the TLS user express the request in literal meaning. The user asked about the admission to the other users.

\section{CONCLUSION}

In summary, the presence of a need to use language for communication with others in a social environment either in synchronous or asynchronous channel is essential in order to achieve a successful social interaction. In an online discussion forum, it is also found that the users employed the speech act of request in various forms and types, namely interrogative, declarative, and imperative sentence either directly, indirectly or literally. In requesting a thing or an information, at the same time a degree of politeness may be expressed. However, the degree of politeness of a request is determined not only by the selection of directness level, but also by the users' choice of strategy, which in some situations would constitute an appropriate choice of the directness level. 


\section{REFERENCES}

Akkaya, Aslihan. 2014. Language, Discourse, and New Media: A Linguistic Anthropological Perspective. Language and Linguistics Compass; Vol. 8, No. 7, pp. 285-300.

Baron, Naomi S. 1998. Letters by Phone or Speech by Other Means: The Linguistics of Email. Language \& Communication; Vol. 18, No. 2, pp. 133-170.

Christie, Christine. 2015. Epilogue. Politeness Research: Sociolinguistics as Applied Pragmatics. Journal of Politeness Research, 11 (2), pp. 355-364.

Chun, Dorothy, Kern, Richard, \& Smith, David. 2016. Technology in Language Use, Language Teaching, and Language Learning. The Modern Language Journal; Vol. 100, No. 1, pp. $64-80$.

Crystal, David. 2001. Language and the Internet. UK: CUP.

Darics, Erika. 2010. Politeness in Computer-Mediated Discourse of a Virtual Team. Journal of Politeness Research, Vol. 6, Issue 1. doi: 10.1515/jplr.2010.007.

Davis, Boyd, Brewer, Jeutonne, \& Brewer, Jeutonne Patten. 1997. Electronic Discourse: Linguistic Individuals in Virtual Space. Suny Press.

Eisenstein, Jacob. 2013. What to Do About Bad Language on the Internet. In Proceedings of the 2013 Conference of the North American Chapter of the Association for Computational Linguistics: Human Language Technologies, pp. 359-369.

Flores-Salgado, Elizabeth, \& Castineira-Benitez, Teresa A. 2018. The Use of Politeness in WhatsApp Discourse and Move 'Requests'. Journal of Pragmatics; pp. 79 - 92.

Herring, Susan. 1996. Computer-Mediated Communication: Linguistic, Social, and Cross-Cultural Perspectives; Vol. 39. Amsterdam: John Benjamins Publishing.

Hewitt, Jim. 2005. Toward an Understanding of How Threads Die in Asynchronous Computer Conferences. The Journal of the Learning Sciences; Vol. 14, No. 4, pp. 567-589.

Kavanagh, Barry. 2016. Emoticons as a Medium for Channelling Politeness within American and Japanese Online Blogging Communities. Language \& Communication; Vol. 48, pp. 5365.

KhosraviNik, Majid. 2017. Social Media Critical Discourse Studies (SM-CDS). Handbook of Critical Discourse Analysis; pp. 582-596.

Kiesler, Sara, Siegel, Jane, \& McGuire, Timothy W. McGuire. 1984. Social Psychological Aspects of Computer-Mediated Communication. American Psychologist; Vol. 39, No. 10, p. 1123.

Locher, Miriam. 2010. Introduction: Politeness and Impoliteness in Computer-Mediated Communication. Journal of Politeness Research: Language, Behaviour, Culture; Vol. 6, No. 1, pp. 1-5.

Nastri, Jacqueline, Pena, Jorge, \& Hancock, Jeffrey. T. 2006. The Construction of Away Messages: A Speech Act Analysis. Journal of Computer-Mediated Communication; Vol. 11, No. 4, pp. 1025-1045. 
Schmerling, Susan. 1982. How Imperatives are Special and How They aren't. Papers from the Parasession on Non Declaratives: Chicago Linguistic Society, ed. by Robinson Schneider, Kevin Tuite, and Robert Chametzky, pp. 202-218.

Searle, John. 1969. Speech Acts. Cambridge: Cambridge University Press.

Searle, John. 1975. A Taxonomy of Illocutionary Acts. Minneapolis: University of Minnesota Press.

Sum, Winnie \& Lee, Cynthia. 2013. (Im)politeness and Disagreement in Two Hong Kong Internet Discussion Forums. Journal of Pragmatics; Vol. 50, No. 1, pp. $52-83$.

Soffer, Oren. 2010. "Silent Orality": Toward a Conceptualization of the Digital Oral Features in CMC and SMS Texts. Communication Theory; Vol. 20, No. 4, pp. 387-404.

Stæhr, Andreas, \& Madsen, Lian Malai. 2015. Standard Language in Urban Rap-Social Media, Linguistic Practice and Ethnographic Context. Language \& Communication; Vol. 40, pp. $67-81$.

Taleghani-Nikazm, Cermen. 2012. Politeness in Computer-Mediated Communication. The Encyclopedia of Applied Linguistics.

Thomas, Emmah, \& Biriyai, Alabo. 2014. Online Discussion Forum: A Tool for Effective StudentTeacher Interaction. International Journal of Applied Science-Research and Review; Vol. 1, No. 3, pp. $111-116$.

Trosborg, Anna. 2011. Interlanguage Pragmatics: Requests, Complaints, and Apologies; Vol. 7. Berlin: Walter de Gruyter.

Walther, Joseph. 2012. Interaction through Technological Lenses: Computer-Mediated Communication and Language. Journal of Language and Social Psychology; Vol. 31, No. 4, pp. $397-414$.

Watts, Richard J. 2003. Politeness. Cambridge: Cambridge University Press.

Wierzbicka, Anna. 2003. Cross-Cultural Pragmatics. Berlin: Walter de Gruyter Inc.

Yazdanfar, Shiler, \& Bonyadi, Alireza. 2016. Request Strategies in Everyday Interactions of Persian and English speakers. SAGE Open; Vol. 6, No. 4. Doi: 2158244016679473.

Zappavigna, Michele. 2012. Discourse of Twitter and Social Media: How We Use Language to Create Affiliation on the Web; Vol.6. London: A\&C Black. 